Acta Pó́tica 37•2

julio-diciembre

$2016(116-123)$

RicARDO MARTínez LACY

Instituto de Investigaciones Filológicas

lacy@unam.mx

\title{
La literatura judía y la historia entre la guerra de los Macabeos (167 a. C.) y la rebelión de Bar Kokba (135 d. C. $)^{1}$
}

\section{Jewish Literature and History \\ Between the War of the Maccabees (167 BC) \\ and the Bar Kochba Rebellion (135 AC)}

1. Droysen postuló la existencia de una época helenística en la que se dio la fusión de la cultura europea clásica y la asiática oriental. Le dio ese nombre, que se encuentra atestado por primera vez en el segundo libro de los Macabeos (4.13), donde designa la adopción de la cultura, la manera de pensar y el idioma griegos (Bichler: 5-22). El resultado de esa síntesis, según el mismo autor, fue el cristianismo. No me parece necesario argumentar la importancia de estas ideas, pero sí señalo que, en esa perspectiva, es fundamental examinar el desarrollo de la cultura judía en esos años y su relación con la cultura griega. Todo indica que ese desarrollo se dio sin conflictos entre la conquista de Alejandro y el reinado de Antíoco IV Epifanes, pero a partir de entonces se dieron una serie de rebeliones y movimientos de masas hasta que los judíos fueron definitivamente derrotados una vez que su país ya había sido anexado al Imperio Romano, bajo el emperador Adriano. Apenas me parece nece-

1 Texto de una ponencia presentada en el II Congreso Internacional de Estudios Clásicos en la UNAM, septiembre de 2008. 
sario decir que este desarrollo incluye el surgimiento del cristianismo y del judaísmo rabínico.

En este proceso, es importante la literatura porque desde su origen el judaísmo se ha regido e, incluso, se define por medio de una ley escrita a la cual se le fueron agregando libros, algunos aceptados como canónicos, que fueron formando la Biblia, y otros no, los Apócrifos del Antiguo Testamento. En esta época se empieza a escribir una literatura judía más profana, con Filón de Alejandría, que escribió libros de religión, historia y filosofía, y Flavio Josefo, historiador. Este corpus literario conforma el testimonio más directo de la helenización judía, de ahí su importancia histórica.

2. Empezaré por trazar un panorama de la literatura histórica. En primer lugar, están los dos primeros libros de los Macabeos, aceptados como canónicos por los católicos y rechazados por los protestantes por iniciativa del propio Lutero, que negó autenticidad a todos los libros del Antiguo Testamento no conservados en hebreo. Filón escribió Contra Flaco y Embajada a Cayo; Josefo, la Guerra judía, las Antigüedades judias, una Vida sobre sí mismo y un tratado polémico Contra Apión. Entre las narraciones ficticias hay que agrupar los libros III y IV de los $\mathrm{Ma}$ cabeos, José y Asnat, Judtih y el tercer libro de Esdras. El Eclesiástico de José Ben Sirá es "una colección desordenada de dichos sobre temas muy diversos" (Delcor: 416) y forma parte del género sapiencial. Hay obras apocalípticas como el corpus de Enoc y capítulos añadidos a $D a-$ niel. Se cuenta con todo un género que consiste en falsos testamentos, por ejemplo, de Abrahán, Isaac y Jacob. Hay una supuesta Epístola de Jeremías y una Epístola de Aristeas. También de esta época provienen los Oráculos sibilinos. A todo esto hay que agregar la conocida como literatura rabínica y los manuscritos del Mar Muerto.

Haré un análisis ideológico de este gran corpus tomando como hilo conductor la relación entre helenismo y judaísmo que, como se verá, no fue nada rígida.

3. Las obras históricas tienen su antecedente en los libros bíblicos de los profetas, clasificados entre los libros históricos en la Biblia de Jerusalén, la traducción oficial católica (IX): En realidad, como los autores de 
esa traducción reconocen, los libros de Josué, Jueces, Samuel y Reyes son el relato de las relaciones entre Yavé y su pueblo - los judíos - y el mensaje fundamental es que cuando el pueblo elegido cumple con la alianza, prospera, y sufre cuando se aleja de ella.

Las Crónicas, los primeros dos libros de Esdras y Nehemías fueron escritos entre 300 y 200, cuando Judea formaba parte del reino helenístico de Egipto. El primero es una reinterpretación idealista de la época de los reyes y sobre todo del reinado de David, el resto se ocupa del regreso del exilio babilónico y la reconstrucción del Templo de Jerusalén.

Los primeros dos libros de los Macabeos son el relato de la rebelión de los judíos contra la "abominación de la desolación", o sea la profanación del Templo y su dedicación a cultos paganos y cómo esto provocó el levantamiento en armas de Matatías y sus hijos, los Macabeos, hasta que éstos lograron tomar Jerusalén y restaurar el culto tres años después de la instauración de cultos helénicos.

El libro primero de los Macabeos fue escrito en hebreo por un judío palestino, pero sólo se conserva en griego; el segundo es el epítome de una obra en cinco libros escrita por un judío de nombre Jasón de Cirene.

Según los dos primeros libros de los Macabeos, varios factores incidieron en este proceso doloroso, pero al fin afortunado para los judíos. Primero, la causa de la profanación del Templo fue el cúmulo de pecados del pueblo de Yavé; esta desolación hizo que los fieles lo comprendieran y reconocieran sus faltas y, de ese modo, las expiaran. Finalmente, los triunfos militares no se debieron a la fuerza, pues los sirios superaban a los judíos, sino al favor de dios.

Hay que notar que ninguno de los primeros libros de los Macabeos presenta una exposición en orden cronológico, y no se puede comprender el desarrollo de la rebelión con base en su solo testimonio.

Raffaelle Cantarella llama historia apologética a las obras históricas de Filón de Alejandría - Contra Flaco y Sobre la embajada a Cayo-y no le falta razón (248).

Flaco Avilio era el legado imperial en Egipto en tiempos de Calígula y cuenta Filón —nacido hacia 15 a.C. y muerto hacia 50 d.C.- , que entre 38 y 40, el legado en cuestión se dedicó a perseguir implacablemente a los judíos, destruyendo primero sus sinagogas y prohibiendo luego 
la ley mosaica y despojándolos de sus derechos políticos y privilegios sociales (VIII.53) hasta que los declaró extranjeros (VIII.54) pero, acusado por el rey judío Agripa I , fue mandado ignominiosamente a Roma (XIV), donde sufrió la persecución de sus enemigos y se le exilió a Andros, donde murió ejecutado, cuando ya se había arrepentido de sus fechorías contra los judíos ("The works of Philo").

Hay que recordar que este fin fue el mismo que tuvo el enemigo de los Macabeos, Antíoco IV Epifanes ya que, según los libros de los $\mathrm{Ma}$ cabeos (1 Ma6.1-16;2Ma 1.10-6 y 9), su arrepentimiento llegó a tal extremo que se convirtió al judaísmo.

Salta a la vista que Contra Flaco tampoco sigue un orden cronológico, sino literario, lo cual le confiere efectividad retórica, pero hace confuso el desarrollo de los acontecimientos.

La Embajada a Cayo es más apologética que histórica y Filón dedica la mayor parte de ella a referir los discursos de los embajadores judíos que querían hacer entender a Calígula por qué se negaban a erigir una estatua con su imagen en el Templo de Jerusalén y por qué ello no representaba falta de respeto hacia él. Es bien sabido que este emperador se consideraba un ser divino y esperaba que sus súbditos lo reconocieran como tal. Filón lo expone muy claramente sin decirlo expressis verbis.

Flavio Josefo estaba del lado de los rebeldes cuando empezó la guerra judía, que estalló en 66 d.C., pero se pasó al bando romano y se convirtió en cliente del procurador Vespasiano y de su hijo Tito y, cuando aquél ascendió al trono imperial, le fue conferida la ciudadanía romana, de ahí el nombre de Flavio, que era el de la nueva dinastía.

Después de la guerra, que terminó con la toma de Jerusalén y la destrucción total del Templo en 70, Josefo escribió un relato sobre ella, la Historia de la guerra judía contra los romanos, que inicia deplorando la parcialidad de autores que no nombra y propone presentar una narración justa de los acontecimientos, pero ya desde la introducción (B.J. I.10) acusa a los judíos de facciosos (stasiastai): "El que fue la misma discordia interna la que arruinó [a los judíos]... y que los que atrajeron la potencia de los romanos en contra de su voluntad, y las llamas sobre el Templo sagrado fueron los tiranos de los judíos, fue testigo el propio emperador Tito, que en toda la guerra sintió lástima del pueblo, oprimido por los facciosos..." 
En efecto, el fundamento de su estrategia de interpretación consiste en atribuir la derrota de los judíos al hecho de que actuaron en contra de la voluntad de Yavé, que consistía en que aceptaran su subordinación política a los romanos y, por lo tanto, su incorporación al imperio y que fueron los mismos judíos los culpables de la destrucción del Templo, por lo que debían aceptar su derrota.

Josefo escribió su historia primero en arameo y luego publicó la versión griega, que se conserva actualmente, entre 79 y 81 , durante el reinado de su patrón, el emperador Tito, a quien había conocido cuando acompañaba a su padre Vespasiano, que comandaba el ejército romano que combatía a los rebeldes y a quien le profetizó su ascenso a emperador.

Doce años más tarde Josefo publicó las Antigüedades judias y su Vida. La primera obra es similar a las de Beroso sobre la historia de Mesopotamia y la de Manetón sobre Egipto, que habían sido escritas para explicar a los griegos en su propio idioma la cultura y la historia de las regiones que acababan de conquistar. A la misma necesidad con respecto a los romanos responde la nueva obra de Josefo, que es una historia en veinte libros sobre toda la historia judía desde Adán hasta el inicio de la guerra de los judíos, por lo que es un complemento de la Historia y precisamente su relato termina cuando el de ésta empieza.

La Vida es la autobiografia más antigua que se conserva y responde a la necesidad que tenía su autor de justificar su cambio de bando en contra de su propio pueblo.

Contra Apión es una defensa de la antigüedad del judaísmo, anterior a las culturas griega y romana, lo cual es cierto.

4. Así como el segundo libro de los Macabeos no es la continuación del primero, los otros dos son obras independientes. El Tercero ni siquiera se refiere a los Macabeos, sino que su tema es la persecución de Ptolomeo VII Euergetes en contra de los judíos en Egipto y la retribución divina en su contra. El Cuarto cuenta patéticamente los martirios que sufrieron los judíos a manos de los sirios porque no querían cometer sacrilegios como comer carne de puerco, y la ejecución de siete hermanos en presencia de su madre porque todos unánimemente se negaron a abjurar de la religión. En ellos se insinúa la idea de una vida después de la muerte para los santos y seguramente esto ha llevado a la iglesia 
católica a reconocer como santos a estos siete hermanos, únicos antes de Cristo.

José y Asnat es un cuento romántico escrito hacia el cambio de era que desarrolla la afirmación del Génesis (41.45) de que el faraón hizo casar al casto José con Asnat. Según el relato, ella era hija de un sumo sacerdote egipcio y desdeñaba a todos los pretendientes hasta que conoció a José, renunció a sus dioses e hizo penitencia por siete días hasta que se le apareció un arcángel que le anuncia que José será su prometido. El mismo arcángel se le había aparecido también al que iba a ser el novio y se lo había anunciado, así que después de algunos obstáculos, los jóvenes se casan. Parece que el mensaje consiste en que los judíos pueden casarse con extranjeras que se convierten al judaísmo.

5. El libro de Judith es considerado deuterocanónico por los católicos, lo cual significa que se le reconoce una canonicidad de segunda clase. Se ascribe al siglo II a. C. y se supone que toma como modelo las guerras macabeas. Relata cómo una muchacha devota engaña al general asirio Holofernes, que sitiaba la ciudad fabulosa de Betulia, lo emborracha y le corta la cabeza. Al descubrir el asesinato, los asirios, despavoridos, se escapan y levantan el sitio.

El Tercer libro de Esdras es considerado apócrifo. Fue escrito en Egipto entre las guerras macabeas y el fin de la época helenística. La mayor parte de su contenido son extractos de los otros dos libros de Esdras con la excepción de un relato sobre tres pajes del rey persa Darío, uno de los cuales lo convence de la restauración del Templo de Jerusalén.

Parece que el libro de Tobías se escribió en el año 200 en arameo y cuenta las aflicciones de una familia, un personaje que se volvió ciego y una muchacha a la que se le mueren los pretendientes: Dios hace que los personajes se casen y él recupere la vista.

6. El Eclesiástico es el nombre cristiano de la Sabiduría de Jesús Ben Sirá. La obra fue escrita originalmente en hebreo a principios del siglo II a. C., pero sólo se conserva entera la traducción al griego del nieto del autor, realizada a fines del mismo siglo. Es expresión de la piedad que movió a los jassidim — los piadosos - a seguir a los Macabeos. 
7. El corpus de Henoc es un conjunto de libros que sólo se conservan completos en etíope, pero parece que originalmente fueron escritos en arameo entre los siglos II a. C. (la guerra de los Macabeos) y el i a. C. (antes de la guerra judía). Consta de varias partes, pero la más interesante me parece la apocalíptica. Apocalipsis quiere decir revelación y sus cultores sostienen que Dios no sólo se ha revelado a Moisés sino que ha habido varias revelaciones. Los mormones sostienen que la última ocurrió en el siglo XIX d. C. Al parecer, este libro, con la segunda parte de Daniel, forman las primeras obras apocalípticas. Según este corpus Dios se le apareció al patriarca antidiluviano Henoc y le reveló que el Señor de los Espíritus elegiría al Hijo del Hombre que un día vendría a juzgar a los buenos y a los malos.

8. La literatura judía de la época helenística es expresión de la helenización de los judíos y testimonia el surgimiento del cristianismo y del judaísmo rabínico, por lo que forma parte de la génesis de las tres religiones monoteístas que se practican en la actualidad. Su conocimiento es fundamental.

\section{BIBLIOGRAFÍA}

Bichler, Reinhold. "Hellenismus". Geschichte und Problematik eines Epochenbegriffs. Darmstadt: Wissenschaftliche Buchgesellschaft, 1983.

Delcor, Mathias. "The apocrypha and psuedepigrapha of the Hellenistic period", en W. D. Davies y Louis Finkelstein (eds.). The Cambridge history of judaism. Volume two. The Hellenistic age. Cambridge: University Press, 1989.

Cantarella, Raffaele. La letteratura greca dell'età ellenistica e imperial. Firenze: G.C. Sansoni, 1968.

"The works of Philo". Artículo en línea disponible en $<$ http://www.earlychristianwritings.com/yonge/book36.html $>$ [fecha de consulta: 30 de noviembre de 2015]. 
RicARDo MARTínez LACY

Licenciado en Historia por la Universidad Nacional Autónoma de México y doctor en Historia Antigua por al Facultad de Estudios Clásicos de la Universidad de Cambridge. Investigador del Instituto de Investigaciones Filológicas de la UNAM. Ha impartido clases de licenciatura y maestría en la Facultad de Filosofía y Letras y en la Facultad de Estudios Superiores Acatlán, ambas de la UNAM; en la Universidad de Münster Guillermo de Westfalia (Alemania) y en la Universidad Autónoma de Barcelona, entre otras. Ha publicado Rebeliones populares en la Grecia helenística (México, UNAM, 1995); Historia e historiadores de la antigüedad clásica ( $2^{\mathrm{a}}$ ed, México, Fondo de Cultura Económica, 2004); Inscripciones helenísticas sobre los ejércitos y la guerra (México, edición del autor, 2008). Su línea de investigación es la hermenéutica de la historia. 